\title{
EL AMOR AL VENENO. SOBRE EL MUNDO SIMBOLICO DE LAS DROGAS
}

\section{Pilar de Miguel Moreno}

La palabra fármaco viene del término griego Phármakon que reúne los dos conceptos de remedio y veneno. En el Corpus Hippocraticum el phármakon se utiliza como sustancia exterior al cuerpo capaz de producir una acción favorable o desfavorable y como purgante, khatarsis. Pero también el pharmakós era la víctima propiciatoria destinada a purificar a la ciudad de sus males (1).

Esta dualidad va a presidir el destino de las drogas. A su uso tradicional con fines mágico-religiosos o terapéuticos, sujeto a normas y prohibiciones, se añadirá posteriormente otro tipo de uso que tendrá que ver con el placer sin dejar por eso de ser ajeno a las otras dos condiciones. Surge así una nueva pasión que, oscilando entre la excitación y la analgesia, actuará como purgante del amor entendido como relación de dicha y de sufrimiento recíproca y simétrica entre dos sujetos.

Voy a tratar de ver, a lo largo del siglo diecinueve y principios del veinte, y a través de algunos textos literarios y de otros médicos, cómo se configuran diversas representaciones sobre el placer y el displacer en relación primero con el opio y la morfina y luego con la cocaína.

Thomas De Quincey, en sus Confesiones de un inglés comedor de opio de 1821 (2), se pregunta por qué llegó a ser habitual consumidor de opio. "Durante mucho tiempo me entregué a mis prácticas con el único fin de crearme un estado artificial de grata excitación». Pasaba épocas sin tomarlo para renovar el placer, pero una vez que lo tiene que usar para "mitigar el dolor en su grado máximo" se convierte ya en consumidor diario. " $¡ O$ pio, terrible agente de placeres y de sufrimientos inimaginables! », dirá más adelante protestando incluso contra Coleridge por haberle atribuido que se habituó a la sustancia persiguiendo voluptuosidades y no por el camino del dolor físico (3). 
El dolor, más que actuar aquí como una coartada, parece ser la condición misma del placer, y. lo aleja de cualquier sospecha. Si este es el origen, el flechạzo de la pasión, su posterior desenlace lo valorará en proporción al encadenamiento al que se ve sometido. Así, a medida que va formando parte de su vida, observa que pasar un día sin tomar opio es como plantearse que sus pulmones no respiran o su corazón no late.

Quincey quiere vengar al opio de ciertas calumnias: el opio no adormece la inteligencia, ni la exaltación que provoca va seguida necesariamente de abatimiento. En este sentido compara al vino con el opio: «El vino desordena las facultades mentales mientras el opio, tomado de manera apropiada, introduce el orden, la legislación y la armonía más exquisitos». Es como si el opio a través de ese tono ilustrado se distanciara del mundo de las bajas pasiones propio del exceso alcohólico (Ya en 1736 en Inglaterra, la Gin Act, que elevaba los impuestos sobre las bebidas alcohólicas, se promulgó «para que los alcoholes sean tan caros que los pobres no puedan cometer excesos») (4).

Este sentido del efecto "sublimador» del opio es también señalado por Moreau de Tours (5) cuando en su obra Du Haschisch et de l'alienation mentale afirma que «el opio parece gozar en alto grado de la facultad de desarrollar una especie de estado mixto en el que la razón y la imaginación aparecen equivalentes ". Aunque en un sentido distinto, y con una actitud mucho más ideológica, Baudelaire, en su Poema del hachis (6) compara también a éste con el opio y señala que en el hachís todo es «infinitamente más acelerado, más vehemente que el opio, mucho más enemigo de la vida regular, en una palabra más turbador». Mientras el uno es un seductor apacible, el otro es un demonio desordenado.

Ya en el siglo XX, el médico español A. Pagador, en Los venenos sociales de 1923 (7), refiriéndose a una categoría de opiófagos, alude a la acción afrodisíaca del opio: «los opiófagos sensuales forman una categoría aparte que gozan de las delicias de la carne y de la imaginación. El opio en ellos aumenta el psiquismo del acto y alarga la duración del placer. Si bien, tras un uso prolongado o abuso, la voluptuosidad acaba por ser esencialmente intelectual.»

Hay pues un uso sabio y sensual del opio y otro excesivo que convierte al goce en algo puramente intelectual, alejado de lo sensible. Esta anulación de la sexualidad lo aproxima a mi entender a las propuestas del Marqués de Sade sobre la saciedad. Pero si en éste, llegar a la apatía sexual a través de la reiteración del acto aberrante es la culmina- 
ción de un proyecto de liberación, en los opiófagos sería una consecuencia del propio veneno y por tanto un triunfo de la Naturaleza.

Al final de su obra, Quincey, siempre con una cierta ambigüedad, nos habla de los males del opio y de éste como motivo de infelicidad. Ha convertido su vida en la repetición de un acto único, donde sólo le está permitido el juego engañoso con la dosis. Sin embargo, el tener al opio como amo absoluto le ha salvado de los dolores de la vida, le ha permitido ser, en sus palabras "un señor pero sin tierra».

Con los avances científicos y, en el terreno de la medicina, con el desarrollo de la farmacología y de la anestesia, se produce también la democratización de los placeres tóxicos, mediante lo que los psiquiatras llaman el «contagio por imitación». A partir de ahora "la felicidad puede comprarse con un penique y llevarse en el bolsillo del chaleco y los éxtasis portátiles encerrarse en una botella de medio litro" (8). Engels ha descrito en La situación de la clase obrera en Inglaterra de 1845 la frecuencia con que las obreras inglesas dan opio a sus hijos para poderse marchar al trabajo. El opio, es decir el beneficio económico de él derivado, ha desatado guerras y el alcohol ha regado la Communne; los militares franceses que han visto en éste la causa de la apatía de la defensa de la patria han tomado medidas prohibitivas anticipándose a la sociedad civil (9).

La necesidad de soportar un trabajo en el que la explotación se hace salvaje lleva a utilizar objetos extravagantes con fines de evasión. Tal situación parece reflejarse en una noticia aparecida en El Siglo Médico en noviembre de 1890 y que lleva por título «El Naftalismo»:

«América, la tierra clásica de las excentricidades, acaba de revelarnos un nuevo género de borrachera. En Bostón hay un gran número de fábricas de caucho para cuya purificación emplean la nafta. Pues bien, en una de ellas se ha observado que la casi totalidad de las obreras estaban en perpetuo estado de borrachera. Se las vigiló y se averiguó que se emborrachaban aspirando a placer los vapores que se escapaban de las calderas de nafta. Las mujeres declararon que este funesto abuso había llegado a ser para ellas casi una necesidad.»

Voy a considerar ahora brevemente algunos momentos del discurso médico y psiquiátrico desde el concepto de narcótico hasta la aparición del de toxicomanía.

«Los venenos narcóticos son aquellos que producen narcotismo: estupor, aplanamiento, parálisis y apoplegía y a veces movimientos convulsivos» dice Pedro Mata en su Tratado de Medicina Legal (10), donde 
el opio, junto al hidrógeno, el gas del alumbrado o el cloral, entra dentro de las intoxicaciones accidentales o con fines criminales.

En el Tratado Frenopático de Giné y Partagás (11) el opio figura en el capítulo del tratamiento de la alienación mental y no en la parte nosográfica. Se recomienda, a pesar de sus contraindicaciones, por su acción sedante del dolor físico, restaurador del sueño artificial y «capaz de interrumpir el funcionamiento cerebral mitigando la intensidad de los fenómenos afectivos, la exagerada sensibilidad moral de los maníacos y melancólicos y el sufrimiento de la hipocondría».

Hasta aquí los venenos y los remedios van por separado. Moreau de Tours ha visto silenciado por la psiquiatría su intento de convertir el hachís en objeto de experimentación en relación con el sueño y la locura. Para los psiquiatras, la apetencia tóxica será un enigma fisiológico pero también psicopatológico y moral.

La morfina, aunque aislada a principios de siglo, no se generaliza hasta su último cuarto, a la vez que se introduce la jeringuilla subcutánea (la cual, más allá de su uso médico, da lugar a la ketomanía o manía de inyectarse por inyectarse). Más médica que el opio por sus efectos y también por el interés que suscita entre la profesión médica, será el modelo de iatrogenia y también del concepto de toxicomanía, perversión instintiva en la que la búsqueda consciente y voluntaria del veneno figura en primer plano. Será pues un vicio y no una verdadera psicosis. Esta condición de droga perversa polimorfa es bien recogida en estos versos de Villaespesa (12):

«Sus rojos labios sáficos, sensitivos y ambiguos a la par piden besos de hombre y de mujer, sintiendo la nostalgia de los faunos antiguos, cuyos labios sabían alargar el placer.

Ama los goces sádicos, se inyecta de morfina, pincha a su gata blanca. El ether la fascina y el opio le produce un ensueño oriental.»

En la antípodas de esas aberraciones literarias está el dipsómano morfínico, "verdadero enfermo", degenerado superior cuya lucha contra la irresistible atracción del veneno, seguida de fracaso, le lleva al arrepentimiento y a tener vergüer.za de sí mismo (13).

Nuestro Juarros, en Los engaños de la morfina, folleto divulgador de 1920, denuncia el hábito de inyectarse como «una pretensión de superioridad, un querer pasar por hombres de mundo». Arremete contra 
los literatos modernos «que han entonado himnos hiperbólicos al placer de envenenarse lentamente. Su inspiración en el orientalismo frondoso no es sino la consecuencia de su escasez de temas». Junto a estos literatos vacíos menciona a Sade, «narrador de aberraciones anatómicamente imposibles». La morfinomanía no es para Juarros sino el sustituto de una sexualidad debilitada.

Logre, en 1922 (14), se planteaba cómo el opio «medicamento por excelencia del dolor físico y psíquico puede ser también un tóxico que no provoque como otro disgusto y aversión sino un apetito y placer mórbidos. Esta auténtica paradoja de la biología supondría un verdadero error del instinto de conservación al confundir un veneno con un alimento". Este pesimismo respecto a la biología recuerda el de Freud cuando, tras el episodio de la cocaína, ve frustradas sus espectativas de que los hombres sean capaces de anhelar algo que les beneficie sin perder por ello el temor a su exceso.

Con la cocaína se introduce la androginia en el mundo de la drogas. Freud, en 1884 (15), al recomendarla por sus efectos estimulantes, parece situarla en el ámbito de la masculinidad: «resulta valiosa en aquellos casos en los que el objetivo primordial es aumentar la capacidad física del cuerpo (...). Este tipo de situaciones aparecen en tiempos de guerra, durante los viajes, en escaladas de montañas y en expediciones de otro tipo.» Freud emplea el dinamómetro en sus pruebas con la droga en un intento de dar uniformidad a sus efectos y por tanto exactitud científica. Su acción como afrodísiaco le interesa muy secundariamente; lo que a él más le atrae es la estimulación de la mente.

Sin embargo, ya en los años veinte, Maïer y sobre todo Logre (16) la define como "la droga femenina por excelencia». Si el morfinismo era propio de las mujeres mundanas, dice Logre, la cocaína lo es de las muchachas galantes de Montmartre. No el dolor sino la voluptuosidad va a ser fundamentalmente su puerta de entrada. La cocaína tiene un halo alimenticio y entra por los sentidos: pastillas, vinos, thes, pathés Mariani, cuyo promotor, rico empresario y químico parisino lanza unos Álbums publicitarios que cobran gran popularidad en Francia hasta los primeros años del siglo XX (17).

La cocaína se recomienda para los trastornos funcionales que se van a convertir en preocupación de la moderna psiquiatría. Freud mismo la recomienda para la neurastenia,'vinculándola así con la genitalidad.

En Le Trafic de la Coco de 1914, los cabarets se llenan de mujeres de ojos resplandecientes al salir del lavabo. Se trata de una sexualidad femenina activa. La borrachera de la cocaína no es ya como en la mor- 
fina euforia pasiva sino «alegría activa en movimiento». Quedan lejos los paraísos artificiales; del Nirvana se ha pasado a la voluntad de poder: «La excitación lleva a la mujer a la locuacidad mientras que los hombres empiezan obras de arte o se lanzan a los negocios» (18). Es el triunfo del paso al acto.

\section{NOTAS}

(1) Gracia Guillén, D. et al. (1987): Historia del Medicamente. Barcelona, p. 36 y 86

(2) QuINCEY, Th. De (1984): Confesiones de un inglés comedor de opio. Madrid.

(3) Ibid., p. 73.

(4) Szasz, T. (1985): Ceremonial Chemistry. Florida, p. 187.

(5) Moreau de Tours (1980): Du Hachisch et de l'alienation mentale. Paris. Es la reimpresión de la edición de 1845 .

(6) Baudelaire, Ch. (1983): Los paraisos artificiales. Madrid, p. 51.

(7) Pagador, A. (1923): Los venenos sociales. Opio, morfina. Barcelona.

(8) Quincey (1984), p. 74.

(9) Fouduet, P.; Borde, M. de (1979): Le roman de l'alcool. Paris. p. 161

(10) Mata, P. (1886): Tratado de Medicina y Cirugía Legal. Madrid.

(11) Giné y Partagás (1875): Tratado teórico práctico de Frenopatología. Barcelona, p. 271 y ss.

(12) Villaespesa, F. (1954): Poesias Completas. Madrid. Tomo I, pp. 130 y 1.187

(13) Roger, G. H. et al. (1922): Nouveau Traité de Médecine. París. El capítulo de intoxicaciones por el opio está redactado por J. B. Logre y el de la cocaína por éste y Dupré.

(14) Ibid., p. 318 y ss.

(15) Freud, S. (1984): Estudios sobre la cocaina. Barcelona, p. 110.

(16) ROGER (1922): p. 409

(17) Huertas, R. (1987): «Búsqueda de paraísos y evasión de realidades: la droga en el siglo XIX», Historia 16. Año XIII, núm. 133. Madrid.

(18) ROGER (1922): p. 413. 